\title{
Effects of tertiary vs quaternary scopolamine on water and air drinking in rats*
}

\author{
M. L. DISSINGER, Rider College, Trenton, N.J. 08602 \\ and \\ W. J. CARR, Beaver College, Glenside, Pa. 19038
}

Nine thirsty rats were allowed to water-drink or air-drink for $1 \mathrm{~h}$ beginning $30 \mathrm{~min}$ after receiving injections of scopolamine hydrochloride, scopolamine methylnitrate, or physiological saline. Relative to performance under saline, both forms of scopolamine suppressed water and air drinking $(p<.01)$. Scopolamine $\mathrm{HCl}$ suppressed water and air drinking more than did scopolamine methylnitrate $(\mathrm{p}<.05)$.

Since the discovery of air drinking by Hendry \& Rasche (1961), most of the research on the phenomenon has been aimed at showing how the response or its determinants are similar to or different from its obvious analog, water drinking. Consider first the similarities. Rats exhibit similar consummatory patterns whether they are water or air drinking. For example, the lick rates and the interlick intervals are similar (Oatley \& Dickinson, 1970), and both responses are accompanied by washing movements (Hendry \& Rasche, 1961). Both responses increase with water deprivation but not with food deprivation, and both can inhibit subsequent water intake (Hendry \& Rasche, 1961; Williams, Treichler, \& Thomas, 1964). Both air and water drinking can be induced by hypertonic saline injections (Carr, Levin, \& Dissinger, 1968) and by certain schedules of food reinforcement in hungry rats (Mendelson \& Chillag, 1970). When water deprived, desalivate rats both air- and water-drink less than control animals (Mendelson, personal communication). Finally, both responses appear promptly in weanling rats having no prior experience with drinking tubes (Riccio, Hamilton, \& Treichler, 1967).

On the other hand, there are certain dissimilarities between air and water drinking, as well as in the effects of certain determinants upon them. The water-drinking response satiates more quickly than does the air-drinking response (Oatley \& Dickinson, 1970), and the inhibitory effect of air drinking upon subsequent water intake is more transient than that of water drinking (Williams, Treichler, \& Thomas, 1964). These differences probably stem from the different

*This investigation was supported in part by U.S. Public Health Service Research Grant HD-00345 from the National Institute of Child Health and Human Development. postingestional consequences of the two responses; although both produce distension of the stomach and intestine, only water drinking produces absorptive effects (Oatley \& Dickinson, 1970).

A number of investigators have hypothesized that rats air-drink because the sensory consequences simulate those of water drinking-both responses cool the mouth and tongue. This hypothesis is supported by the report that thirsty rats prefer to lick a piece of cold dry metal over one maintained at room temperature and that air drinking is suppressed when the airstream is rendered warm and humid (Mendelson \& Chillag, 1970). This hypothesis might also be tested by using compounds known to affect differentially the central vs the peripheral mechanisms likely to be involved in water regulation.

In the present experiment, air and water drinking were observed in thirsty rats which earlier had received injections of scopolamine hydrochloride, scopolamine methylnitrate, or physiological saline. Both forms of scopolamine are anticholinergic compounds, but at the dosages here employed, it seems likely that the tertiary form (scopolamine HCl) affects primarily the central mechanisms involved in water regulation, while the quaternary form (scopolamine M.N.) affects primarily the peripheral mechanisms (Goodman \& Gilman, 1956, p. 543). However, Stein (1963) and Houser (1970) believe that only the centrally active form suppresses water intake, while Gerald \& Maickel (1969) believe that both forms suppress water intake to about the same extent. The former investigators stress the regulation of water balance by central mechanisms; the latter investigators stress regulation by both central and peripheral mechanisms. Therefore, the present experiment was designed to help resolve this issue as well as to compare the effects of these compounds upon water vis air drinking. SUBJECTS

The Ss were nine male rats of the Long-Evans strain, each weighing approximately $500 \mathrm{~g}$ initially. Prior to the experiment, each $S$ was reduced to $80 \%$ of its ad lib weight by adjusting the volume of its single daily water ration. They were caged individually in an air-conditioned room and had constant access to Rockland Mouse/Rat Diet (Complete).

\section{APPARATUS}

For the water-drinking tests, the home cages were fitted with $50-\mathrm{ml}$ graduate cylinders. Air-drinking tests were conducted in three operant conditioning chambers, measuring $8 \times 11 \times 11$ in. Each chamber contained the operator's end of a telegraph key and a stainless steel drinking tube. The key was situated $0.5 \mathrm{in}$. above the floor, and the tube was positioned $1 \mathrm{in}$. above and $1 \mathrm{in}$. to the right of the key. Air passed from a rotary pressure pump ( 3 psi), through a $\mathrm{CaCl}$ desiccator and a chamber containing activated charcoal and silica gel, to a solenoid-operated air valve which was normally open to an air line leading well away from the test site. Depressing the telegraph key activated the air valve for $3 \mathrm{sec}$, diverting the air stream through a second line ending on the drinking tube.

\section{PROCEDURE}

The Ss received three air- and three water-drinking tests, each lasting for $1 \mathrm{~h}$. Thirty minutes before a test, Ss received an intraperitoneal injection of approximately $0.5 \mathrm{ml}$ distilled water (adjusted for body weight) containing one of three compounds: scopolamine hydrochloride $(0.4 \mathrm{mg} / \mathrm{kg})$, scopolamine methylnitrate $(0.4 \mathrm{mg} / \mathrm{kg})$, or physiological saline $(0.9 \%) .^{1}$ The Ss were assigned randomly to a counterbalanced order of the three treatments for both the air- and water-drinking tests, and at least $72 \mathrm{~h}$ elapsed between treatments. The Ss received their daily water ration immediately after testing.

Prior to the experiment, Ss were trained for $1 \mathrm{~h} / \mathrm{day}$ for 10 days to barpress for air-drinking reward. On the first day, they received free access to a constant stream of air. On the second day, they received $15 \mathrm{~min}$ of free access, followed by $45 \mathrm{~min}$ of a CRF schedule. Thereafter, Ss remained on the CRF schedule to the criterion of at least 200 responses/hour. Five of the original 14 rats failed to meet criterion, and they were excluded from the experiment. The remaining nine $S s$ were retrained on the day prior to each air-drinking test.

RESULTS

Table 1 shows the effects of the three compounds upon the mean water intake and the mean number of 
Table 1

Mean Water Intake and Mean Number of Barpresses for Air Under Three Drug Conditions During 1h Tests $(N=9)$

\begin{tabular}{|c|c|c|c|}
\hline $\begin{array}{l}\text { 10-Min } \\
\text { Interval }\end{array}$ & $\begin{array}{c}\text { Scopolamine } \\
\mathrm{HCl}\end{array}$ & $\begin{array}{l}\text { Scopolamine } \\
\text { Methylnitrate }\end{array}$ & $\begin{array}{r}\text { Saline } \\
(0.9 \%)\end{array}$ \\
\hline \multicolumn{4}{|c|}{ Mean Water Intake (ml) } \\
\hline $\mathbf{1}$ & 10.7 & 15.7 & 19.9 \\
\hline 2 & 0.7 & 0.2 & 1.8 \\
\hline 3 & 0.3 & 0.8 & 2.5 \\
\hline 4 & 0.3 & 0.9 & 1.7 \\
\hline $\mathbf{5}$ & 0.8 & 1.4 & 1.7 \\
\hline 6 & 0.4 & 0.8 & 1.5 \\
\hline $1-6$ & $13.2 *+$ & $19.8 *$ & 29.1 \\
\hline \multicolumn{4}{|c|}{ Mean Number of Barpresses for Air } \\
\hline $\mathbf{1}$ & 120 & 154 & 218 \\
\hline 2 & 127 & 211 & 260 \\
\hline 3 & 91 & 162 & 242 \\
\hline 4 & 112 & 137 & 206 \\
\hline 5 & 78 & 193 & 187 \\
\hline 6 & 80 & 126 & 182 \\
\hline $1-6$ & $608 *+$ & $983^{*}$ & 1295 \\
\hline
\end{tabular}

$* p<.01$ (different from saline) $; \neq p<.05$ (different from scopolamine methylnitrate)

barpresses for air during the 1-h tests. The data are presented by $10-\mathrm{min}$ intervals to show how the performance varied within tests.

A nalyses of variance, using a two-factor repeated measures design, revealed that differences due to compounds were significant for water drinking $(F=30.80, \quad d f=2 / 16$, $p<.01)$ and for air drinking $(F=9.36, \quad d f=2 / 16, \quad p<.01)$. Differences across 10 -min intervals were also significant for water drinking $(F=178.31$, df $=5 / 40, p<.01)$ and for air drinking $(F=4.03$, $d f=5 / 40$, $p<.01)$. The interaction of Compounds by $10-\mathrm{min}$ Intervals was significant for water drinking $(F=11.18, \mathrm{df}=10 / 80, \mathrm{p}<.01)$ but not for air drinking ( $F=0.92$, df $=10 / 80, p>.05$ ).

Additional analyses showed that both forms of scopolamine suppressed water and air drinking, relative to performance under the saline control (Dunnett tests, $\mathrm{p}<.01$ ), and that scopolamine hydrochloride suppressed both water and air drinking more than did scopolamine methylnitrate (Newman Keuls tests, $p<.05$ ).

\section{DISCUSSION}

The present results confirm Oatley \& Dickinson's (1970) observation that thirsty rats satiate more quickly when water drinking than when air drinking. From the data in Table 1 , it may be ascertained that Ss injected with physiological saline ingested more than $68 \%$ of their mean hourly water intake during the first 10 -min interval of the 1-h test, whereas they emitted less than $17 \%$ of their mean hourly number of barpresses for air during that same interval.

Using dosages comparable to those employed in the present experiment, Stein (1963) and Houser (1970) reported that water intake in thirsty rats is suppressed by the centrally active scopolamine hydrochloride, but not by the peripherally active scopolamine methylnitrate. On the other hand, Gerald \& Maickel (1969) found that both the tertiary and quaternary forms of scopolamine suppress water intake to about the same extent. The results of the present experiment fall between those reported by the other investigators. Here, both forms of scopolamine suppressed water intake in thirsty rats, but the tertiary form proved to be a more effective suppressor than the quaternary form. The resolution of these conflicting findings awaits the outcome of further research, aimed at separating more precisely the central from the peripheral mechanisms involved in water regulation. The conflicting findings may stem from slight procedural differences or from the use of different strains of rats. Nevertheless, the point seems clear that, under the present experimental conditions, air and water drinking are alike in that both are suppressed in thirsty rats by the anticholinergic compound, scopolamine.

CARR W J LEVIN B. H, \& DISSINGER, M. L. Water drinking and air drinking: Some physiological determinants. Psychonomic Science, $1968,13,23-25$.

GERALD, M. C. \& MICKEL, R. P. Evidence for peripheral cholinerpic components in thirst-induced water consumption. International Journal of Neuropharmacology, 1969, 8, 337-346. GOODMAN, L. S., \& GILMAN, A. The pharmacological bosis of therapeutics. (2nd ed.) New York: Macmillan, 1956.

HENDRY, D. P., \& RASCHE, R. H. Analysis of a new non-nutritive positive reinforcer based on thirst. Joumal of Comparative \& Physiological Psychology, $1961,54,477-483$.

HOUSER, V. P. The effects of adrenergic and cholinergic agents upon eating and drinking in deprived rats. Psychonomic Science, 1970, 20, 153-155.

MENDELSON, J., \& CHILLAG, D. Tongue cooling: A new reward for thirsty rats. Science, 1970, 170, 1418-1420.

OATLEY, K., \& DICKINSON, A. Air drinking and the measurement of thirst. Animal Behaviour, 1970, 18, 259-265.

RICCIO, D. C., HAMILTON, D. M.. \& TREICHLER, F. R. Effects of age and ingestive experience on air-drinking behavior in the rat. Psychonomic Science, 1967, 7, 295-296.

STEIN, L. Anticholinergic drugs and the central control of thirst. Science, 1963, $139,46-48$.

WILLIAMS, J., TREICHLER, F, R. \& THOMAS, D. R. Satiation and recovery of the "air drinking" response in rats. Psychonomic Science, 1964, 1, 49-50. NOTE

1. Scopolamine hydrochloride and scopolamine methylnitrate were kindly supplied by Dr. Larry Stein, Wyeth Laboratories, Radnor, $\mathrm{Pa}$ 